\title{
Internship as a Mean for Integration. A Critical Study
}

\author{
Hala Alaraj ${ }^{1}$ - Majsa Allelin ${ }^{2}$ - Matilda Amundsen Bergström ${ }^{3}$ (D) \\ Camilla Brudin Borg ${ }^{3}$
}

Published online: 18 August 2018

(C) The Author(s) 2018

\begin{abstract}
Creating internships for newly arrived refugees and immigrants is a well-established part of the Swedish national integration program and is seen as a strategy to speed up immigrants' establishment process. One common belief is that the workplace is expected to give the newly arrived trainee necessary language training, as well as contextual and cultural knowledge. Here, the transferring direction of knowledge is from the Swedish workplace to the receiving newly arrived trainee. However, it is rarely discussed whether the trainee will bring valuable knowledge to the organization, or what the relational aspects of the internship should look like. In this paper, we develop the analysis of internships as a mean for integration in Sweden, by analyzing what trainees and their supervisors experience in terms of knowledge transfer and development. By interviewing trainees (4) and supervisors (5), the aim of this paper is to discuss ideas and practices in an internship program for refugees that The University of Gothenburg started in 2015. The interviews focus on the structural and organizational level, though individual experiences also play a central role. Theoretically, the analysis is interdisciplinary and a cross-cut between organizational theory and cultural studies, especially the work of Sara Ahmed. Our results show that the trainee is seen both as a resource and as someone who represents multiculturalism, hospitality, and the altruism of the university and its employees. The trainee is expected not only to integrate in a productive way, but also to stand out in non-productive areas, such as the social context.
\end{abstract}

Keywords Internship · Labor market · Integration · Sweden · Skills · Workplace culture

All authors contributed equally to this work.

Matilda Amundsen Bergström

Matilda.amundsen.bergstrom@lir.gu.se

1 The Department of Literature, History of Ideas, and Religion, The University of Gothenburg, Gothenburg, Sweden

2 The Department of Social Work, The University of Gothenburg, Gothenburg, Sweden

3 The Department of Literature, History of Ideas, and Religion, The University of Gothenburg, Gothenburg, Sweden 


\section{Introduction}

According to the European Parliament (2017), over two million people crossed the European borders in 2015 due to war and international crises. Of those two million, 162,877 applied for asylum in Sweden - an unprecedented number of asylum seekers in the country (Migrationsverket 2017). In the Swedish public debate during 2015, the situation was described as the largest humanitarian crisis since World War II (Radio Sweden, Studio Ett, 11 mars 2015). No other political question was debated more at the time. In 2015, the government made historical changes in the countries refugee laws, making it more difficult to be granted asylum (Lag 2016:752). At the same time, a myriad of initiatives were launched by individuals, groups, and organizations at all levels in society, aiming to formulate constructive ways forward with regard to welcoming and integrating newly arrived refugees into Swedish society. The University of Gothenburg was one such organization. It rapidly decided to offer 80 internships for newly arrived academics in Gothenburg (Björned 2015) and have since then continued to develop activities in connection with migration, refugees, and scholars at risk.

Following this pioneer initiative, the Swedish government commissioned all Swedish governmental agencies, including the universities, to offer internships to refugees who had recently been granted asylum, from 1 April 2016-31 Dec 2018 (The Government 2016).

In the Ministry of Finance's assignment to the governmental agencies, the aim and measures are formulated as such:

The increased immigration means opportunities for Sweden and can contribute to a growing and more dynamic economy. The Government's focus is to make sure that newly arrived women and men get an employment as soon as possible in order to help develop Sweden. [...] The aim of this assignment is to give recently arrived work seekers, women as well as men, the opportunity to develop their Swedish language skills, increase their networks and gain knowledge of the different types of work performed within governmental agencies, which could increase their possibility to find future work regardless of the sector of the labour market. (The Government 2016, p.2)

The document states that by integrating the newly arrived into the Swedish labor market, the trainee program could benefit the Swedish economy as well as the country's new inhabitants.

The document is underpinned by a strong belief in the positive outcome of developing language skills for the individual trainee. A similar focus on language development is evident in recent research (Sandwall 2010) as well as in official Swedish policy. The public, and mandatory, Swedish language education program (SFI: Swedish for Immigrants) has since 2006 adopted a "practical work placementstrategy." The strategy explicitly aims to speed up the immigrant's transition from school-supported language learning to being an integrated member of the society, speaking the language, having a real job, and being self-sufficient (Sandwall 2010). In that respect, the above-mentioned assignment is in line with, and an extension of, previous policy. 
In the assignment, the newly arrived trainees are expected to "increase their networks and gain knowledge of the different types of work performed within governmental agencies" which is assumed to "increase the possibility to find future work regardless of the sector of the labour market." This assumption reveals a pre-existing idea of how knowledge will be transferred in the program, from the Swedish workplace to the receiving trainee.

By investigating how trainees and their supervisors experienced the internship program, the aim of this study is to discuss how these experiences can be understood in relation to the national goals and measures. Combining sociological theory and method with the field of humanities, we are also able to contribute to an interdisciplinary critical perspective on internship as a mean for integration.

\section{Method}

The study builds on four in-depth interviews with persons that either have or have had an internship at The University of Gothenburg at the time of the interview, together with five in-depth interviews with supervisors at The University of Gothenburg. The supervisors were all employed at the university at the time of the interviews, and spoke as such. The trainees were placed in many at different departments. For each trainee, one or two supervisors were appointed from the department's staff. Nobody was forced to be a supervisor, but rather members of staff were encouraged to sign up if they wanted to volunteer. The supervisors acted as guides and mentors for the trainees. The interviews were conducted during the second semester of 2016. The trainees as well as the supervisors were placed at different departments, were appointed to different kinds of tasks, and given administrative as well as more research-related positions within the university organization. The departments were free to choose what tasks the internship would entail.

The reason for the relatively small number of informants is twofold. First of all, the study has a qualitative approach, meaning we do not seek to be explanatory nor show any specific causality. Instead, the validity of the study springs out of what the informants' statements and the national and organizational goals represent in relation to theory (Van Maanen 1979). Secondly, the study is a pilot study. It was initiated shortly after The University of Gothenburg implemented the trainee program, which causes a natural limitation of the empirical sample. Our aim with the study is mainly to develop research questions and perspectives that could later on be pursued in a larger study.

Both the authors and the respondents were associated to The University of Gothenburg at the time of the interviews, but there is no closer affiliation between them. The interviews were conducted in Swedish and were semi structured (see Kvale 2007). Two of the trainees had certain questions explained in a language they were more familiar with during the interviews. Each interview took about $1 \mathrm{~h}$ each. The interview guide for the trainee concerned questions such as educational or working background, how the internship was perceived and experienced, and what kind of tasks were appointed to the trainee. It also investigated the experienced relationship to colleagues and what expectations the trainee had before, during, and after the internship. The interview guide for the supervisors targeted questions about how they got involved in the trainee program 
and how they organized the internship, the tasks appointed to the trainee, and their beliefs about learning outcome for both parties.

Since the study has a qualitative approach that seeks to understand the experiences of the trainees and supervisors, the interviews were thematically analyzed (see Vaismoradi et al. 2013). To be able to grasp the conditions of the trainee vis- $a$-vis the supervisors on their own premises, the interviews with the trainees and supervisors were initially analyzed separately. After the coding was done, the interviews were read in relation to each other. In this second, merging step, the final coding was done and with it the structure of the article.

All names are feigned and substituted for ethical reason. As the internship program at The University of Gothenburg is relatively small and recently started, we have chosen not to name the individual departments. This does not affect the validity of the study as its focus lies on a structural perspective, targeting the university in general as a space for knowledge transformation and knowledge processing.

\section{Theoretical Perspectives}

\section{Implementing Organizational Changes}

To be able to understand the context in which both the trainees and the supervisors are working, we will outline some theoretical points of departure. Firstly, we will discuss concepts within organizational theory, and secondly, we present a critical perspective drawing on the work of Sara Ahmed. Through this interdisciplinary approach, the article attempts to deepen the understanding of beliefs and outcomes of the trainee program.

\section{Conceptual and Operational Knowledge}

Within the field of organization theory, the terms practical/operational knowledge and cognitive/conceptual knowledge have been used to describe different learning processes (see for example Fiol and Lyles 1985; Romme and Dillen 1997; Hedberg 1981; Shrivastava and Mitroff 1982; Senge 1990). Practical/operational knowledge involves learning concrete tasks and work methods, such as handling computer systems or writing protocols - assignments that do not require a broader understanding of the organization one is working within. Cognitive/conceptual knowledge, however, refers to an overall understanding of the organization, its history, and desired future. It involves having a coordinating position and, in some cases, even a vision.

This kind of division is often dependent upon which position or status an individual has in the organization (Bunderson and Reagans 2011). The higher up in the hierarchy, the more probable it will be for the person to engage in the conceptual field, whilst a person in a lower or precarious position most often is directed to practical tasks.

Another factor that affects this division is the informal social life that occurs in every organization (Knoche and Castrogiovanni 2015). It should also be mentioned that attaining cognitive/conceptual knowledge, practical/operational ones, is mainly an analytical distinction. A learning process in real life is hard to divide into reified abstractions, and it would not even be correct to do so (Alvesson 1993). However, 
on an analytical level, when pointing out the power structure - for instance the division of manual and intellectual labor-it can be a useful tool.

\section{The Knowledge Economy, "Hard" and "Soft" Skills, and the Merging of Space and Body}

As part of the concept of life-long learning, a more common way to view knowledge is by making a distinction between "hard skills" (sometimes referred to as technical skills) and "soft skills" (sometimes referred to as cultural skills) (see for instance the European Network of the Heads of Public Employment Services 2011). In contrast to the terms conceptual and operational knowledge, these categories cut across the organizational hierarchy, as employees and employers are all expected to master both hard and soft skills. While "hard skills" are defined as "specific job-related technical abilities," "soft skills" involve social competences such as adaptation, openness, and positive attitudes that will enable the employee to communicate, co-operate, and work well within the organization (Urciuoli 2008, 2010).

In the so-called "knowledge-based" economy which demands flexibility, since the labor market is ever changing, the ability to learn becomes more important than what is actually being learned. Soft and social skills, which includes the above-mentioned competences, become a resource. "Soft skills," meaning the ability to adapt, becomes a fundamental quality for the individual worker. To be able to meet and handle fluctuations, individuals must learn how to stay innovative and positive - qualities that do not automatically come with "hard skills" or formal education (see Shulz 2008).

Among Swedish advocates of the "skill" concepts are The Confederation of Swedish Enterprise (Svenskt Näringsliv) and the liberal think tank Forum for Reforms, Entrepreneurship and Sustainability (Fores). According to these market-friendly lobbying parties, social skills are becoming more and more important. It is even stated that abilities such as cultural competences are sometimes more crucial than technical skills (Fores 2014). Since technical needs, and technology, are constantly changing, there is no point in relying on formal qualifications. To cite OECD:

The demands on learners and thus education systems are evolving fast. In the past, education was about teaching people something. Now, it is about making sure that individuals develop a reliable compass and the navigation skills to find their own way through an increasingly uncertain, volatile and ambiguous world. (...) Today, schools need to prepare students for more rapid economic and social change than ever before, for jobs that have not yet been created, to use technologies that have not yet been invented, and to solve social problems that we do not yet know will arise. (...) Put simply, the world no longer rewards people just for what they know - Google knows everything - but for what they can do with what they know. (OECD 2015, Schooling redesigned)

What is often neglect in these discussions, however, is the preceding processes of acquiring "soft skills." For a long time, sociology and cultural studies have emphasized the importance of symbolic and cultural capital - a knowledge of language, customs, social codes, and norms of the surrounding society — which accompanies one's social background (Bourdieu 1979/2010). Acquiring social skills is not something that can be 
planned a priori, but rather something that must be understood as a consequence and in relation to specific hierarchies and power structures and to a certain symbolic and cultural capital.

To enable an analysis of the processes through which soft skills are acquired, as well as a discussion of how (global and organizational) power hierarchies with regard to, for example, language, and race/ethnicity influence these processes, it is necessary to complement our descriptive organizational theory with a critical perspective. In this article, Sara Ahmed's critical and phenomenological studies on the relationships between employees and organizations provide this perspective (Ahmed 2007).

In "The phenomenology of whiteness," Sara Ahmed discusses the relationship between bodies and (institutional) space, noting that "[p]ublic spaces take shape through the habitual action of bodies" (Ahmed 2007, p.156). Ahmed offers two important points. Firstly, she notes that such habits fade into an invisible background - we become used to them and stop noticing them. Secondly, this interconnection between body and space makes spaces, according to Ahmed, extensions of certain bodies. This is what makes a person feel at home. If our habits are similar to the space in which we move and to the people who are there, we fit in the space. If, on the other hand, our habits are unlike the space, we do not fit in. This will be experienced as discomfort, insecurity, and as being constantly exposed. Furthermore, it makes us aware of ourselves and of our difference, similar to a double consciousness (Du Bois 1989). The difference might be described as one between moving freely and constantly running into walls (Ahmed 2007, pp. 160-163). From such a perspective, it is the merging of space and body that, hopefully, enables the trainee to move freely through a workplace (and in extension - the Swedish labor market).

\section{The (Risky) Importance of Organizational Key Figures}

One of the greatest challenges when implementing new systems, as in this case implementing a new trainee program for incorporating immigrants into the university as a work place, is the relationship between the individuals (micro level) and organizational culture (meso level). Just because an initiative or formal directive about new work procedures is decided, it does not mean it will replace collective memories, structures, traditions, and informal hierarchies. For it to be successfully implemented, individuals will have to relate and integrate the information and directives in a sustainable way. Thus, collective, organizational knowledge is more than the sum of all individuals, and learning processes must be understood dialectically between the individual and the organization. As Crossan et al. puts it: "Complex organizations [such as the Universities] are more than ad hoc communities or collections of individuals. Relationships become structured, and some of the individual learning and shared understandings developed by groups become institutionalized as organization artefacts" (Crossan et al. 1999, pp.524).

For new systems or knowledge development to last and for organizational changes to be enduring, ideas must be integrated on a collective level (Crossan et al. 1999; Bierly et al. 2000). This requires, first of all, that the leaders of the organization must acknowledge the benefits of the change. But the employees are also important. In situations where changes are initiated by individuals that have an influential position, fellow workers must legitimize the propositions and be willing to integrate changes on 
a more systematic level. If not, the changes will be fragmentized in their implementation and arbitrarily done, based on personal interests and adaptation. Thus, long-lasting changes — both cognitive/conceptual and practical/operational—must go beyond its key figures and become collective actions and a collective memory. Lastly, implementation of changes is also affected by the organizational structure. The flatter the structure, the more accessible and dynamic will the learning process be. At the same time, the more hierarchical an organization is, the easier it is to institute changes in a systematic way. In both cases, however, vague information and expectations hinder the realization of change (Crossan et al. 1999).

Implementing a trainee program for newly arrived is not necessarily something that would increase the competitiveness of the departments nor contribute to the ranking system under which the universities are conditioned. If formal resources are not offered to the program, much of it will be dependent on motivated individuals, which makes the initiative highly vulnerable.

\section{Empirical Findings}

In the following, we will present what the trainees and the supervisors experienced in terms of knowledge transfer and development. For reasons of confidentiality, we have chosen to call the four trainees T1, T2, T3, and T4 and the five supervisors S1, S2, S3, S4, and S5.

\section{The Experience and Expectations of the Trainee}

\section{Understanding "the System"}

Most importantly, every trainee hoped that their internship would help them establish themselves on the Swedish labor market - generally or specifically within academia. This movement towards work was connected, in the interviews, to the accumulation of two types of knowledge. On the one hand, the trainees spoke of practical knowledgethe technical, hard skills required to complete specific tasks. A working knowledge of Swedish — with an emphasis on professional vocabulary - can be included in this category. On the other hand, the trainees felt the need for another type of knowledge that they found more difficult to pinpoint. T1 spoke of understanding "the system," T2 about gaining "experience," and T3 about learning how a Swedish university "works." T4 explained this double-sided project:

T4: I had some expectations regarding language skills development, having a better knowledge about working environment in Sweden, and have more experience, which will provide me more space in the Swedish labour market in the future.

It seems that working in, but also working with a space-a specific space such as a university department or a more abstract one such as the Swedish labor market - not only requires practical knowledge, but also a mastery of a cultural competence (in a 
broad sense) that is required of the organization, that might be described as a set of "soft skills." This view is also shared by representatives for the university. For instance, in an interview about the internships which was published in the university's journal, the project manager states that one aim of their internship program is "providing possibilities to learn about Swedish society and workplace culture" (GU Journalen 2016:5, p. 22). This second, soft, learning process is important both from the perspective of the workplace and from that of the trainees. But it is harder to make explicit what such knowledge of "society" and "workplace culture" consists of, how it is learned, and why it is important. In an effort to shed light on this underexplored aspect of the internship experience, we turn to discuss the trainees' engagement with their workspace.

\section{Habit Worlds}

Underpinning the above-mentioned aim is an unspoken assumption that in order to work in and with a space, one must fit that space and the people who work there. Drawing on Ahmed, this assumption can be described as an ideal of similarity- the space must be familiar to the trainee, and the trainee to the space. ${ }^{1}$ The internship is, from that perspective, a process of body and space becoming alike.

Based on our interviews, this process of merging space and body take on two different forms. Firstly, the space can be adapted to fit the body. Such willingness to change the space to fit the body is most commonly experienced as a feeling of being welcomed. Several trainees talked about the importance of being given their own space, their own office with a laptop. T2 spoke of a surprise and joy when he came to work and a room was prepared for him, with his name on the door:

T2: It was a really nice surprise [the first day], because I received my own room with my name, it was on the door, and I didn't think that would happen. I was really happy.

Nothing made T2 feel more welcome than the fact that the physical environment had been changed to accommodate him. Naturally, everybody needs an office space to work, but an office also gives the trainee privacy-functioning as a form of safe space - and very concretely conveys a willingness to adapt the workspace to the trainee. This will increase the level of belonging to the work place, giving the trainee the feeling of being part of the team, as well as being welcome. The symbolic importance of the physical environment was also stressed by T3, though in a negative way. She spoke about the frustration of constantly getting lost, not finding her way "home," and working in lunchrooms or other public spaces. In her case, the experience of being a stranger, of running into walls, took physical shape.

Changing the space to fit the body can be done concretely. But it might also be done abstractly; by adapting the internship to fit the trainee. S4, for instance, mentions flexibility with regard to a trainee unable to perform the task that the department had in mind. There are also examples of departments making the internship fit the specific skills of the trainee, enabling the trainee to enrich the department's ordinary activities.

\footnotetext{
${ }^{1}$ Ahmed would phrase it as a necessity of the space being an extension of the trainee. She writes: "White bodies are comfortable as they inhabit spaces that extend their shape" (Ahmed 2007, p. 158).
} 
One example is T4, who had previous experience in communication and university administration. She approached her department with the idea to launch a conference on the topic of university internship. In this case, the department adapted the trainee's tasks to fit her previous work experience. T4, together with her supervisors, arranged the above-mentioned conference where a number of university departments and organizations participated.

For most of the interviewees, however, their schedules and assignments were predetermined. To some extent, the same can be said for the expected outcome of the internship. Supervisor, S4, spoke of a hesitation to accept a too highly trained trainee, since they felt unsure about how to structure the situation to produce a pre-determined outcome:

S4: We were offered a person who was... or is... incredibly competent, who has been a lawyer previously. And I would have been happy to take that person another time - to teach mainly, but I'm worried that this person might have too much competence to find it [the internship] fun. It has to be a challenge too, so you feel that you evolve.

This attitude might be put down to a desire to provide a rewarding experience for the trainee-it can be daunting to come into a workspace without clear instructions about what to do there. But at the same time, the wish to pre-determine the internship also reveals an unwillingness to adapt the workspace - thought of more abstractly as the work situation rather than the actual rooms - to fit the trainee, leaving the responsibility of the "fit" between workspace and trainee up to the trainee's ability to adapt.

Secondly, thus, body and space can merge by the body adapting to fit the space. Though not spoken of in such explicit terms, this seems to be the common approach and the natural point of departure. It is telling that the above-mentioned goal of the internship is formulated as a one-way process of the trainee learning about Swedish society and work culture, rather than being spoken of as an intra-action between trainee and workspace, in which both sides explore how they can adapt to each other. In our examples, one department held the door "open" for the initiatives from the trainee (the example of the conference). Other supervisors and trainees describe a more preorganized internship, where tasks were sometimes decided beforehand, or decided by the supervisors and departments rather than suggested by the trainees. The reason might be that many supervisors saw language learning as the most important aim of the internship, together with learning the Swedish workplace culture.

From this perspective, one of the most crucial aspects of the internship is the question of language.

\section{The Importance of Swedish}

Most trainees faced difficulties with the language. Interestingly, the problem was not the professional vocabulary, but rather social conversations during lunch or coffee breaks. The difficulty came from the speed of talking, and from the fact that the topics that were being discussed often demanded a high level of language and slang. T4 spoke of one situation when colleagues were discussing their skiing vacation in the north of Sweden: 
T4: For example, some employees were discussing their skiing up in the north of Sweden mentioning certain names of equipment's as well as names of familiar places to other Swedish, but not for persons outside Sweden. This complexity in language use cause uncertainty and caused me to self-withdrawal. As I do not understand the topic they are talking about so I will not contribute in the conversation.

This complexity in language use causes a feeling of fear to not being able to contribute to the conversation, resulting in self-withdrawal and difficulties to interact with other employees. This is another example of how the space is not fitted to accommodate the trainee.

A related question is that of culture, specifically workplace culture but also culture in a wider sense. One obvious example is, naturally, the Swedish tradition of "after work," of going to a pub or bar together after work. This tradition, which always includes alcohol, might exclude many people from taking part in the "workplace culture" that they are supposed to learn about, making any such knowledge useless. T1 highlighted how certain cultural differences meant that she could not or did not feel comfortable engaging in some social activities. Though T1 was not excluded from them, she was faced with the choice between excluding herself or breaking her cultural codes. This is a painful choice - even more so considering the precarious situation that the trainee is in with regard to the provider of the internship. Beneath the welcoming phrase of the invitation was, thus, a less friendly message — an impossible ultimatum, again causing self-withdrawal. It is important to note that our interviewees experienced similar situations differently. In contrast to T1, T3 was engaged in many social activities with her Swedish colleagues outside the workplace. This might have been due to the length of the internship: T3 had a 6-month-long internship, whereas T1's was much shorter. But it is also important to consider what cultural norms different people may need to give up to be able to profit from different efforts to be introduced to Swedish "workplace culture."

At this point, it is important to point out the power imbalance between the employees of the department who are at "home," and the trainee who is trying to fit in. In the situation discussed here, such a power dynamic becomes more profound. Some of the factors mentioned above, such as the need for an office, are not limited to refugee trainees but can be thought to be universal. But other aspects of the workspace-body "fit" are specific to these trainees. One such aspect is the question of language.

It is interesting that learning Swedish was stressed by trainees and supervisors alike. With its emphasis on internationalization, the University of Gothenburg has, for a long time, recruited international members of staff. These co-workers, mostly from Western Europe, the USA, and Australia, are rarely required to master Swedish. Both students and staff are accustomed to switching to English to accommodate international staff. In the case of such members of staff, the workspace adapts to fit individual. The trainees, however, are expected to adapt to fit the pre-existing linguistic environment. The question is seldom one of enabling communication - all of the trainees interviewed were highly proficient in English. Tentatively, one might suggest that since the Anglophone international members of staff often are more alike the workspace in other ways - be it culturally, academically, or ethnically, they are "similar enough" to be at home in the workspace without the demand of sharing the Swedish language. The 
trainees on the other hand seem to be perceived as being in a greater need of "fitting in" and therefore requested to master the Swedish language at a level where they are capable of doing the work in Swedish. Language is thus one of the most palpable differences between trainee and workspace, but perhaps also thought to be most "neutral." Another tentative conclusion is that whether it is the space that adapts to the body or the body that adapts to the space is a question of global power hierarchies.

\section{The Experiences and Expectations of the Supervisors}

None of the supervisors were given extra time or resources to engage in the mentorship as the involvement was voluntarily organized and based on personal motivation. The supervising was thus done parallelly with the employee's ordinary work tasks. When asked why they engaged in the project the answers focused on both emotional as well as practical reasons.

Question: How were the discussions about receiving a trainee?

S1: Well firstly, the directives were given from our Head of department... he was the one who presented the university's initiative for us and asked us if we wanted to be involved and take on a trainee. And then our group said, 'yes, we do!' - and one person would be enough, we thought. In that way, we could split the work as well between us... and also, well you know we're read about the situation in Sweden, how it is and all, so it also felt meaningful for many of us to do something. And since it was a voluntary task you'd have to feel that you have something to give and that it's enjoyable as well.

This type of reasoning was widely spread among the supervisors. The reason for engaging in this extra work was partly because of altruistic arguments, albeit concerning different matters. It could be to help the trainee or it could be to gain a feeling of meaningfulness on a personal level. As S1 stated: "It might not be the biggest thing in the world, but it means a lot for the person who gets here [to Sweden]" and that "you get something out of it as a human being." Or as another supervisor, S2, put it:

S2: As being part of a government body, it is my opinion that you have some sort of responsibility, I think there lies a moral obligation to do so... well then of course, one always has a personal motivation as well.

Besides these altruistic arguments, there were also practical reasons why the trainee program was of interest. In the first quote, the supervisor is telling us that they needed to split the work with the trainee which indicates the lack of readiness and formal resources. Consequently, because it was an extra task for the department, and because the departments are under productivity pressure, the trainee was sometimes seen as an extra resource. "Since we have a heavy workload, it would be great if someone could help un-burdening us a bit" (S3) as one supervisor stated. The supervisors therefore hoped that the trainee would have relevant operational skills, "someone with good computer experience such as Word, Excel and other programs" (S4) for example. In other words, the trainee was given a dual role: one that is supposed to learn-"an 
investment," and one that is already competent enough to become a resource- "a return."

Accordingly, when the supervisors reasoned why the internship was important for the trainees, the arguments were quite hands-on. They concerned operational/practical knowledge, learning specific tasks such as computer systems and administrative routines, though two things were mainly emphasized: their ability to practice the Swedish language and getting merits on their CV. These, they stated, were the biggest gains for the trainee. As one supervisor framed it:

S4: (...) as our head coordinator stressed, that they would get the chance to be a trainee in order to practice their [Swedish] language skills. And that was also what we pointed out for those [at the department] who were to meet the trainees: that it is Swedish that is the deal. We know that the directives didn't reach everyone, all the way but... that was really our explicit instructions, that they would practice their language skills and get a merit in their CV, yeah...

The language skill is, as have been pointed out above, a competence that participates in more than one category. In one way, it could be classified as a practical knowledge, a "hard skill." In another way, languages are cultural phenomenon which demand social understanding and sense of nuances. A language includes collective memories, such as emotions and traditions, which is not easy to learn in a formal way. In the interviews, therefore, when discussing the language aspect of the internship, it is easy to see that the cognitive aspects were very close to hand as well.

But interestingly, when the cognitive/conceptual knowledge was mentioned, it was mostly defined by the definitions of "soft skills," such as the trainees' possibility to have a social and cultural exchange.

S5: I think it's a really good possibility for the newly arrived to get an insight of the different parts of society, on different levels. Both socially but also as a training; to be able to practice the language and to get a foot in to society more generally. I think it's really effective in a way.

The cultural aspect was a complicated and conflicting issue. In one way, the supervisors thought it was interesting to listen to the trainees' private experiences and to learn something about for instance the war in the trainee's home countries, their traditions, and perhaps even their religious beliefs. This tended to create a "listening" and pending dynamic while in those cases where the trainee showed signs of assimilation or sameness, the trainee quickly became something familiar and associated with positive qualities. This wasn't just something that occurred during the internship, but something that also affected the actual process of choosing the trainee. One trainee was actually chosen because of the trainee's involvement in sports activities and in the engagement in training young people which was taken as an ambition to learn Swedish and Swedish culture.

It becomes evident that the informal qualifications, the soft skills, are just as crucial as the formal ones. Being the double stranger that the trainee is - both a newly arrived in the country and on the Swedish labor market - the personal qualities (being ambitious, active, social etc.) makes the stranger less strange. In this case, the person earned 
its placement as a trainee due to the fact that the trainee had already showed cultural competence and a soft skill mastery.

During the interviews, the supervisors were mostly concerned with what the trainees could gain from the internship - not what they could contribute with in professional terms. When asked what the department could gain, the answer was often centered around the altruistic/moral aspects combined with the "listening" and pending dynamics described above.

Question: What was your gains having a trainee?

S1: Well I think we've had a whole lot of cultural exchange. We've learned so much about the situation in Syria during our coffee breaks. They've been sharing some of their experiences with us... which I personally find very interesting, to get to know someone with a background that is so different from most of ours. And then... I don't know, for instance the first trainee we had, he's got a job now at the university, that makes me very happy. It feels like you've actually done something. Maybe he could've gotten the job anyway, but it's easier for him after he's got a foot in, and for us to be a part of that feels... [great] You really do feel good as a person, as a human being. And I think we all feel that way. So it's on different levels, that's very positive... yeah.

There were, in other words, moral and cultural aspects in the supervisors' engagement, rather than professional curiosity or professional academic interest. For the trainee, though, the gains were said to be concrete, involving language training, getting "a foot in" the Swedish society and a better CV.

The motivation behind taking on a trainee was in all cases the result of a collective wish to "do something" in the 2015 chaotic European refugee situation. The intention was to "give" and "engage." However good the intention was, a certain charity aspect of such a motivation and action is foregrounded and thus pushing to the background a willingness to pay attention to the real potential beneficiations of the internship, which was stressed in the governmental decree. In the following, we will go on to discuss the structure between trainee and the department employees and make some concluding remarks.

\section{Critical Discussion}

\section{Conflicting Motivations and Cultural Reproduction}

On a national level, the aim of the trainee program has been to integrate the newly arrived into the Swedish labor market (through the means of language learning and work placement). The program has been formulated both as a way for well-educated newcomers to get more specialized work life experience, and as an opportunity for the Swedish labor market to use these "international competences." In the knowledge economy, organizational learning and development is seen as crucial in the processes of reaching competitive advantages (Moingeon and Edmondson 1996). Language training can be seen as one such process (Shin 2016). Being advanced professional learning organizations, the universities have become important platforms when 
branding the nation (Deem et al. 2008; Marginson 2006). Roughly speaking, the name of the nation is today expanding (the continuation of its sovereignty) not through conquest but competition. Attracting a skilled and flexible work force is one way of succeeding in this competition.

On a meso/organizational level, however, this general profitability is not realizable in the internships' initial phases, as the trainee program is characterized by social and professional training. Rather, the program could be viewed as an "investment in human recourses" that will give the organization a competitive advantage in the long term. However, in our findings, it is clear that on a meso level, The University of Gothenburg was not mainly driven by the potential economic and professional gain that the trainee program could bring to the organization (Moingeon and Edmondson 1996). Instead, the aim was to help specific people and society as a whole in a difficult time. This altruistic motivation might explain why the program has been dependent on organizational key figures rather than being implemented on a collective level. The project, as well as the responsibility for knowledge development both for individuals and for the organization, remained on a micro level. Firstly, the University of Gothenburg initially provided internships to help newly arrived refugees without being a part of a national program. Secondly, when the program was implemented - even when it was adapted by the government - the departments did not receive extra resources to work with the trainees. The program was entirely dependent on individual members of staff and their personal, be it altruistic or practical, motivation. The risk with such a set-up is obvious. Crossan et al. emphasizes that in order for change to become permanent in an organization, leading figures must acknowledge the benefits and importance of that change (Crossan et al. 1999). By not granting the necessary resources to the program, heads of departments and the chancellor of the university implicitly undermined the importance of the program, regardless of what they actually said about it. One possible outcome is that the program as well as the potential knowledge development that the trainees could bring to the organization is never integrated at a collective level.

Even though the personal, altruistic motivation of the key figures in the program is understandable, two critical points can be made about it. Firstly, not giving any resources to the supervisors and using the trainees to relieve the existing workload, as was sometimes the case, is to exploit both supervisors and trainees. The supervisor gets an extra task and the trainee does unpaid labor. As the trainees were mostly occupied with tasks that required practical/operational skills, there is a risk of a power hierarchy developing in the organization between trainees and employees (Bunderson and Reagans 2011). Such a development would be a long way both from the altruistic motivation underlined by our respondents and from the view that "international competence" could advance the Swedish knowledge economy (Moingeon and Edmondson 1996).

Secondly, the fact that the trainee program is dependent on the altruistic motivation of the supervisors affects the dynamics of the internship on a micro/interpersonal level between trainee and supervisor. This leads us onto a second critical point. It is important to remember that the trainee has an ambivalent position in the organization. As trainees, he or she is not a fully integrated member of the organization. The trainee was expected to do some work, though not any vital work. Even if the newly arrived had freely accepted and applied for the internships, they had little other choice in a broader perspective, as there were few "real" jobs available. Ahrne (1993) describes the general position of an organization member as half dependent, half free (an 
"organization centaur"). In the case of the newly arrived trainees, however, they must be considered much less free than controlled, as their position at the university is dependent on the good will of other people.

Since the supervisors' work is voluntary and based on personal motivation, the trainee has a dependent position not only with regard to the organization but also to the supervisor's good will (Ahrne 1993). Thus, the interpersonal dynamics between trainee and supervisor tend to become based on social and personal emotions, notably involving certain expectations of the trainee being "grateful," "ambitious," or "curious." As Knoche and Castrogiovanni (2015) have pointed out, access to organizational conceptual knowledge is often dependent on the informal, social life of an organization. With the trainee program, this certainly seems to be the case. In order to gain access to the cognitive/conceptual knowledge necessary for understanding how the university "works," the trainees must perform a certain social role, and demonstrate soft skills such as adaptation and ambition (Urciuoli 2008, 2010). Correspondingly, the supervisors must get to feel that they have done something "unselfish" by helping the trainee and contributing to the ethical goodwill of the organization. To sum up the different levels and the relations between them, the department does something altruistic for the trainee, where the trainee is expected to perform in a certain way and demonstrate certain soft skills (socially and professionally), which eventually is supposed to lead to promote the Swedish labor market and economic growth. This is supposed to leave the trainee with a sense of gratefulness (since it has to do with actual life chances), whereon the university can be content with fulfilling an ethical obligation.

In all, in order for a trainee program to represent an enduring change on a meso level and not be dependent on key figures and their differing motivation, to avoid exploitation, an in order to avoid power imbalances between trainee and supervisor on a micro level, we would suggest that it receives separate funding. Great effort must also go into making the program a collective project with a framework for knowledge development and retention. Altruistic motivation might seem enough at first glance, but to build a program on it has many risks.

\section{The Trainee as Guest}

Despite the heavy emphasis on trainees' social skills, both when recruiting and during the internship, the trainee never becomes a natural, integrated member of the organization. This has to do with organizational as well as social reasons. Firstly, the framing of the trainee as a refugee is so strong in the program, that it risks becoming his or hers primary identity. This framing is done both socially and organizationally. Being a refugee is the whole premise of the trainee's existence at the work place from the beginning. As such, the trainee is labeled as an "organizational centaur" (Ahrne 1993) in a specific way: he or she is considered to be part of the organization but in a profoundly different way and for different reasons than other employees. Is it possible for colleagues and supervisors to reshape this framing? Paired with the explicit demand of learning Swedish, the refugee will have a difficult task trying to fit in to the workspace. Since he or she might lack the "cultural capital" that other employees take for granted (Bourdieu 1979/2010), the trainee is at a disadvantage when it comes to acquiring the required and expected soft skills. Taken together, the process of merging body and space that Ahmed calls the basis for feeling "at home" in an organization 
(Ahmed 2007, 2012) creates a strong indication of, though never made explicit, how welcome the trainee is (and in what way they are welcome) at the university.

Based on our interviews, we would argue that the trainees have been welcomed as guests - as examples of organizational hospitality rather than as an enduring change in the collective memory of the university (Crossan et al. 1999). As Ahmed points out, such a welcoming does not diminish, but rather perpetuates the radical gap between those who belong and those who do not, at the same time as it presents itself as bridging that gap (Ahmed 2012).

One aspect of this has to do with time. It is in the nature of the internship to be limited in time. But trainees as well as supervisors stressed that the internships had been too short, leaving the trainees with too little time to acquire neither the operational nor the conceptual knowledge they were in need of. It is of course a daunting, not to say impossible, task to become "at home" in a space constituted by a strong demand to learn Swedish, being a guest, and it is hardly achievable in the couple of months that is the standard length of the internships. For an internship program such as this not to become an altruistic "decoration," or what Ahmed calls a "non-performative act" (ibid, pp.113-140), but instead be a real possibility for knowledge development in both hard and soft skills, we would therefor suggest that it be prolonged.

Yet another, more complex, factor of the trainees' tacit positioning as guests in an alien space is how they are simultaneously expected to be both similar and different. On the one hand, it is stressed that the trainees must adapt to become alike the workspace. Adaption is an important soft skill in today's labor market (Urciuoli 2008, 2010). Though this is often expressed in terms of language or social skills in the interviews, the ideal of adaption basically means gaining the "cultural capital" required to "fit in" and be similar to the other employees in the organization (Ahmed 2007). On the other hand, many supervisors pointed out that they wanted to interact with the trainees because of their perceived difference - mostly discussed as cultural differences that might bring an unfamiliar, element to the workspace. From that perspective, the trainees' pre-existing cultural capital and soft skills were an asset. However, their pre-existing knowledge was not thought to be professionally useful, but only socially interesting. Though the trainees were expected to learn to become similar to the workspace, they were also expected to be different. The trainee is seen both as someone who could become a resource if he or she assimilates, and as someone who represents desirable diversity. Hence, the trainee becomes someone who is expected to be integrated in a productive way, but at the same time to stand out in the non-productive areas such as the social context.

\section{Charity or a Willingness to Be Enriched?}

The expectations surrounding the praxis of offering a newly arrived academic an internship seem based on a knowledge transfer direction going from the university to the trainee. When any kind of knowledge transfer is mentioned going in the other direction, it is not transferring on a meso/organizational level but only on a micro/ personal level, notably going from the trainee to the member of staff. This knowledge is rarely thought to enrich the organization in other ways than socially, though such a perspective on "international competence" is prevalent both in the governmental assignment and in research on the topic (Moingeon and Edmondson 1996). The member of staff that interacts with the trainee gets an insight in cultural differences 
that is experienced as personally enriching. But the organization does not use the trainee's professional knowledge. It is even reluctant to do so.

For instance, when one supervisor was asked about recruitment, she answered that at one occasion her department had an applicant with high qualifications in law. They turned down the application out of fear that the applicant would not be stimulated. This clarifies the implicit knowledge transfer direction: from the university to the newly arrived trainee. No respondent mentioned that the trainee program could have provided opportunity for the department to have a highly qualified trainee with the means to contribute with both operational and conceptual knowledge to the department-i.e., reversing the knowledge transferring order. One explanation could be that the university, as the managerial organization it is, has a hard time planning for the unexpected. But the reluctance to learn from the trainees is noteworthy, since highly educated individuals apply to become trainees and since the university is even more invested in the ideals of a knowledge-based economy than many other work spaces (Deem et al. 2008; Marginson 2006). The fact that the trainee program was never framed as an opportunity to develop organizational knowledge is remarkable, and telling with regard to the implicit power hierarchies that underpin the program.

A self-awareness of the complex, unequal, relationship between the refugee and the receiving part in an internship could hopefully make the university open up to acknowledging the (in many cases very high) competence, the strong motivation to start a new life and the willingness to share experiences from a professional former life (not just exotic anecdotes at the lunch break). In order for this type of relational knowledge development to happen, however, the space of the university would have to adjust not only on a social level, but also on a formal level.

Open Access This article is distributed under the terms of the Creative Commons Attribution 4.0 International License (http://creativecommons.org/licenses/by/4.0/), which permits unrestricted use, distribution, and reproduction in any medium, provided you give appropriate credit to the original author(s) and the source, provide a link to the Creative Commons license, and indicate if changes were made.

\section{Reference}

Ahmed, S. (2007). The phenomenology of whiteness. Feminist Theory, 8(2), 149-168.

Ahmed, S. (2012). On being included: racism and diversity in institutional life. Durham: Duke University press.

Ahrne, G. (1993). Delvis människa, delvis organisation. Sociologisk Forskning, 1, 59-78.

Alvesson. (1993). Organizations as rhetoric: knowledge-intensive firms and the struggle with ambiguity. Journal of Management Studies, 30(6), 997-1015.

Bierly III, P. E., Kessler, E. H., \& Christensen, E. W. (2000). Organizational learning, knowledge and wisdom. Journal of Organizational Change Management, 13(6), 595-618.

Björned, C. (2015). University of Gothenburg creates 80 trainee positions for refugees. News and Calendar. The University of Gothenburg. http://www.gu.se/english/about_the_university/news-calendar/News_ detail/university-of-gothenburg-creates-80-trainee-positions-for-refugees.cid1347183. Accessed 3 April 2017.

Bourdieu, P. (2010). Distinction: a social critique of the judgement of taste. London: Routledge.

Bunderson, S. J., \& Reagans, R. E. (2011). Power, status, and learning in organizations. Organization Science, 22(5), 1121-1367.

Crossan, M. M., Lane, H. W., \& White, R. E. (1999). An organizational learning framework: from intuition to institution. Academy of Management Review, 24(3), 522-537.

Deem, R., Mok, K., \& Lucas, L. (2008). Transforming higher education in whose image? Exploring the concept of the 'world-class' University in Europe and Asia. Higher Education Policy, 21(1), 83-97.

Du Bois, W. E. B. (1989). The souls of black folk. New York: Penguin Books. 
European Network of the Heads of Public Employment Services (2011) The case for skills. A Response to the Recommendations regarding the Future Role of Public Employment Services under the New Skills for New Jobs Agenda.

European Parliament (2017) EU migrant crisis: facts and figures, published 30-06-2017, attained 2018-07-26. http:/www.europarl.europa.eu/news/en/headlines/society/20170629STO78630/eu-migrant-crisis-factsand-figures.

Fiol, M. C., \& Lyles, M. A. (1985). Organizational learning. Academy of Management Review, 10(1), 803-813.

Fores (2014) Jakten på det nya kapitalet - Sverige i den globala konkurrensen om kompetens. [In search of the new capital - Sweden in the global competition of competences].

Hedberg, B. (1981). How organizations learn and unlearn. In P. C. Nystrom \& W. H. Starbuck (Eds.), Handbook of organizational design (pp. 3-27). New York: Oxford University Press.

Knoche, H. T., \& Castrogiovanni, G. J. (2015). The effects of informal social structures: a cognition-structureaction approach. Organization Management Journal, 12(3), 139-152.

Kvale, S. (2007). Doing interviews (1st ed.). Thousand Oaks: Sage Publications.

Marginson, S. (2006). Dynamics of national and global competition in higher education. Higher Education, 52(1), 1-39.

Migrationsverket (2017) Asylsökande till Sverige under 200-2017 [Asylum seekers in Sweden 2000-2017], attained 2018-07-26 https://www.migrationsverket.se/download/18.4a5a58d51602d141cf41003 /1515076326490/Asylsökande\%20till\%20Sverige\%202000-2017.pdf.

Melin, Thomas (2016).Praktikplatser för nyanlända gynnar alla, GU Journalen 5.

Moingeon, B., \& Edmondson, A. (1996). Organizational learning and competitive advantage. London: Sage.

OECD. (2015). Schooling redesigned: towards innovative learning systems. Educational Research and Innovation: OECD Publishing.

Romme, G., \& Dillen, R. (1997). Mapping the landscape of organizational learning. European Management Journal, 15(1), 68-78.

Sandwall, K. (2010). 'I learn more at school': a critical perspective on workplace-related second language learning in and out of school. Tesol Quartely, 44(3), 542-574.

Schulz, B. (2008). The importance of soft skills: education beyond academic knowledge. NAWA: Journal of Language and Communication, 2, 146-154.

Senge, P. (1990). The fifth discipline: the art and practice of the learning organization. New York: Doubleday/Currency.

Shin, H. (2016). Language 'skills' and the neoliberal English education industry. Journal of Multilingual and Multicultural Development, 37(5), 509-522.

Shrivastava, P., \& Mitroff, I. I. (1982). Frames of reference managers use: a study in applied sociology of knowledge. In R. Lamb (Ed.), Advances in strategic management (pp. 161-182). STAD: JAI Press.

The Government (2016). Uppdrag till statliga myndigheter att ta emot nyanlända arbetssökande för praktik 2016-2018 m.m. Fi2016/00386/ESA. Url: http://www.regeringen.se/490a19/contentassets/c382ae36 fbbe48c0af839d83a87c56dc/uppdrag-till-statliga-myndigheter-att-ta-emot-nyanlanda-arbetssokande-forpraktik-2016-2018-m.m

Urciuoli, B. (2008). Skills and selves in the new workplace. American Ethnologist, 35(2), 211-228.

Urciuoli, B. (2010). Neoliberal education: preparing the student for the new workplace. In C. Greenhouse (Ed.), Ethnographies of neoliberalism (pp. 162-176). Philadelphia: University of Pennsylvania Press.

Vaismoradi, M., Turunen, H., \& Bondas, T. (2013). Content analysis and thematic analysis: implications for conducting a qualitative descriptive study. Nursing and Health Sciences, 15(3), 398-405.

Van Maanen, J. (1979). Reclaiming qualitative methods for organizational research: a preface. Administrative Science Quarterly, 24(4), 520-526. 